\title{
SOCAR Proceedings
}

Reservoir and Petroleum Engineering

\section{КОМПЛЕКСИРОВАНИЕ РЕЗУ ЯЬТАТОВ МОДЕЛИРОВАНИЯ ГРП ПРИ ПРОВЕДЕНИИ ГИБРИДНЫХ КИСЛОТНО-ПРОПАНТНЫХ ОБРАБОТОК И ПРИ ОДНОВРЕМЕННОЙ ИНИЦИАЦИИ ТРЕЩИНЫ ГРП В РАЗДЕДЕННЫХ ИНТЕРВАЛАХ}

\author{
И.Г. Фаттахов ${ }^{1,2}$, Л.С. Кулешова ${ }^{1}$ Р.Н. Бахтизин ${ }^{1}$, \\ В.В. Мухаметшин ${ }^{* 1}$, А.В. Кочетков ${ }^{2}$ \\ ${ }^{1}$ фимский государственный нефтяной технический университет, Уфа, Россия \\ ${ }^{2}$ ПАО «Татнефть» имени В.Д. Шашина, Альметьевск, Россия
}

\author{
Complexing the Hydraulic Fracturing Simulation Results when Hybrid Acid-Propant \\ Treatment Performing and with the Simultaneous Hydraulic Fracture \\ Initiation in Separated Intervals \\ I.G. Fattakhov ${ }^{1,2}$, L.S. Kuleshova ${ }^{1}$, R.N.Bakhtizin ${ }^{1}$, V.V. Mukhametshin ${ }^{* 1}$, A.V. Kochetkov ${ }^{2}$ \\ ${ }^{1}$ Ufa State Petroleum Technological University, Ufa, Russia; \\ ${ }^{2}$ PJSC Tatneft named after V.D. Shashin, Almetyevsk, Russia
}

\section{A b stract}

The purpose of the work is to substantiate and formulate the principles of data generation with multiple results of hydraulic fracturing (HF) modeling. Qualitative data for assessment, intercomparison and subsequent statistical analysis are characterized by a single numerical value for each considered hydraulic fracturing parameter. For a number of hydraulic fracturing technologies, uncertainty may arise due to obtaining several values for the parameter under consideration. The scientific novelty of the work lies in the substantiation of a new approach for evaluating the obtained data series during hydraulic fracturing modeling. A number of data can be obtained both during the formation and modeling of several hydraulic fractures, and for one fracture when calculating in different modules of the simulator. As a result, an integration technique was developed that allows forming a uniform data array regardless of the number of elements in the hydraulic fracturing modeling results.
Keywords:

Hydraulic fracturing;

Acid-proppant hydraulic fracturing;

Hydraulic fracturing of layered rocks;

Hydraulic fracturing modeling;

Pseudo-three-dimensional fracture model;

Data preparation;

Statistical analysis.

(C) 2021 «OilGasScientificResearchProject» Institute. All rights reserved.

Со смещением центра тяжести в добыче жидких углеводородов в сторону залежей с трудноизвлекаемыми запасами возрастает роль и значимость исподьзования методов воздействия на призабойную зону и пласт с целью интенсификации добычи нефти и увеличения степени выработки запасов [1-10].

Важным моментом при этом явдяется создание научно-методической базы, позволяющей обоснованно проводить выбор наиболее эффективных технояогий с целью снижения рисков, повышения успешности и эффективности этих мероприятий [11-20].

Одним из наиболее эффективных методов повышения эффективности разработки низкопро-

*E-mail: vv@of.ugntu.ru

http://dx.doi.org/10.5510/OGP2021SI200577 дуктивных залежей нефти с трудноизвлекаемыми запасами является гидравдический разрыв пласта (ГРП). Однако использование этого метода должно быть строго обосновано с использованием раздичных способов моделирования [21-23].

Рассматриваемые задачи моделирования ГРП - прогноз при планировании и материалы для статистического анадиза проведенных процессов

Моделирование ГРП охватывает комплекс задач. Одними из важных задач явдяются прогноз параметров при подборе скважины и определении технологии ГРП: планируемых параметров создаваемой трещины и технологических параметров процесса проведения ГРП [24-27]. Другой важной задачей является статистический анализ проведенных ГРП по участку разработки, для проведения которого требуется корректно подготовленный массив данных [28-38]. 
Как для планирования, так и для анализа проведенных процессов требуется оценка таких данных, как: объем обработки, типы применяемых пропантов и реагентов, оценка геометрических, фильтрационных параметров трещины по модепи, а также параметры, измеряемые при анализе мини ГРП - эффективность жидкости, чистое давление разрыва, напряжения. Эти параметры сопоставляются с полученными показателями по добыче и при достаточном накопленном объеме данных позволяют уточнять планирование, прогноз и оценку рисков при подборе скважин для ГРП и технологий по скважинам [39-43].

Дия формирования массива данных, пригодного для последующего статистического анадиза, необходимо выделить численный показатель, соответствующий каждому из рассматриваемых параметров. В ряде случаев выбор одного численного показателя из ряда данных требует обоснованного уточнения.

Понятие базовой единицы моделирования, виды и структура базовых единиц

Для ряда новых технологий ГРП не существует соответствующих опций в симуяяторе. В общем случае это требует доработки симулятора, что является дорогостоящим, и не всегда возможным процессом. Тем не менее, если технология подразумевает комбинированную закачку ранее известных стадий, возможно проведение нескольких единиц моделирования отдельно взятых компонентов.

Резудьтат модедирования отдельно взятого компонента назовем базовой единицей моделирования.

Результаты моделирования отдельно взятых компонентов закачки сами по себе не позволят получить достоверные данные, но были найдены способы их корректного объединения - комплексирования.

Рассмотрим случаи комплексирования при проведении гибридного кислотно-пропантного ГРП и при обработке пласта с переслаиванием, что в некоторых случаях требует определения численного показателя.

\section{Рассматриваемые технологии гибридно- го кислотно-пропантного ГРП (КПГРП) и способ компдексирования базовых единиц моделирования для решения поставденных задач}

Термин гибридный ГРП применяется для достаточно широкого спектра технодогий и для рассматриваемых задач требует уточнения. Эффективная часть трещины ГРП, влияющая на продуктивность работы скважины, должна быть закреплена пропантом. В случае, если пласт сложен растворимыми в кислоте породами, эффективная часть трещины может быть создана кислотой. Гибридная технология ГРП в рамках данной работы рассматривается как создание проводимости одновременно кисдотой и пропантом -

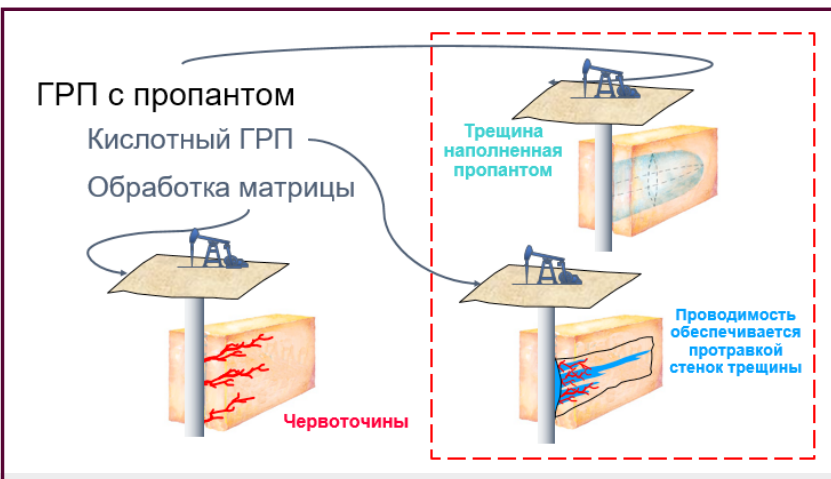

Рис.1. Технологии интенсификации

объединенная технология по классификации на рисунке 1.

Данная технология не предусмотрена симулятором ГРП, но присутствуют отдедьно кисдотные и пропантные ГРП. Это позволяет разбить процесс моделирования такого ГРП на две базовые единицы: кислотную и пропантную.

Структуры базовых единиц моделирования ГРП и кислотный гидроразрыв пласта (КГРП) имеют некоторые раздичия. В таблице 1 представлены значимые для поставленных задач параметры и их наличие в выгрузках симулятора при моделировании.

Чтобы получить резудьтирующую выгрузку, для параметров, присутствующих как в ГРП, так и в КГРП, необходимо определить и обосновать приоритетный источник данных. Кроме того, для ряда параметров необходимо выполнить соответствующие вычисления.

Общий объем смеси разрыва для расчетов ГРП и КГРП не идентичен. Для КГРП не учитывается дополнительный объем, занимаемый частицами пропанта. Для корректного учета объема смеси разрыва, результирующее значение должно быть принято по данным пропантного ГРП.

Общий объем чистой жидкости и масса пропанта по фракциям в данных КГРП отсутствуют. Значения принимается по данным пропантного ГРП.

Эффективность жидкости разрыва присутствует как в модуле пропантного, так и в модуле кисдотного ГРП. Принимаемое значение необходимо выбрать в соответствии с запланированными информационными стадиями. Если планируется тодько пропантный миниГРП, значение будет откалибровано в пропантном модуле и должно быть принято по пропантному ГРП. В случае с миниГРП на основе кислоты резудьтирующее значение принимается по кислотному ГРП. При наличии двух информационных ГРП - отдельно с пропантом и отдедьно с кислотой - рекомендуется коэффициенты фидьтрации откалибровать по типам жидкости, а резудьтирующее значение принять осредненное.

Чистое давление разрыва, в связи со значительным вдиянием пропанта на формирование трещины, принять по данным пропантного ГРП.

Для оценки общей высоты трещины необхо- 


\begin{tabular}{|l|c|c|c|}
\hline \multicolumn{4}{|c|}{ Параметры и их наличие в выгрузках симудятора } \\
\hline \multicolumn{1}{|c|}{ Параметр } & $\begin{array}{c}\text { Выгрузка } \\
\text { ГРП }\end{array}$ & $\begin{array}{c}\text { Выгрузка } \\
\text { КГРП }\end{array}$ & $\begin{array}{c}\text { Принимае- } \\
\text { мое значение }\end{array}$ \\
\hline Общий объем смеси разрыва & + & - & $\Pi$ \\
\hline Общий объем чистой жидкости & + & + & $\Pi$ \\
\hline Масса пропанта по фракциям & + & - & $\Pi$ \\
\hline Эффективность жидкости разрыва & + & + & $0.5 \cdot(П+\mathrm{K})$ \\
\hline Чистое давление разрыва & + & + & $\Pi$ \\
\hline Общая высота трещины & + & + & $\mathrm{max}(П, \mathrm{~K})$ \\
\hline Гидравдическая длина трещины & + & + & $\mathrm{K}$ \\
\hline Длина трещины, закрепленная пропантом & + & - & $\Pi$ \\
\hline Длина трещины, протравленная кислотой & - & + & $\mathrm{K}$ \\
\hline Средняя гидравдическая ширина трещины & + & + & $0.5 \cdot(П+\mathrm{K})$ \\
\hline Ширина трещины, закрепленная пропантом & + & - & $\Pi$ \\
\hline Проводимость трещины & + & + & П+К \\
\hline Объем растворенной породы & - & + & $\mathrm{K}$ \\
\hline
\end{tabular}

Прияечание: П - значение пропантного модуля, К - значение кислотного модуля.

димо учитывать все возможные сценарии. На распространение трещины в высоту оказывает влияние ряд факторов, часть которых может как сдерживать рост высоты, так и способствовать увеличению охвата. Для оценки рисков необходимо принимать внимание максимадьный охват трещины по высоте.

Гидравлическая длина трещины в пропантном модуле может быть занижена в связи с эффектом упаковки трещины пропантом. Тем не менее, оценка гидравдической длины производится, как правило, с точки зрения рисков охвата обводненных зон, либо нежелательных зон, таких как разломы. Таким образом, гидравлическая длина доджна быть принята по кисдотному модулю симулятора.

Эффективная длина трещины, закрепленная пропантом, либо протравленная кислотой определяется в соответствующем модуле и принимается напрямую по результатам расчетов.

Средняя гидравлическая ширина трещины - параметр для обобщенной оценки созданной трещины. Значения, получаемые по пропантному и кислотному модулю, значительно не отличаются. Для корректной оценки принимается среднее арифметическое значений пропантного и кислотного модуля.

Ширина трещины, закрепленная пропантом, определяется только по пропантному модулю и принимается по этому значению.

Проводимость трещины при кислотно-пропантном ГРП создается закрепленной пропантом эффективной частью трещины и кислотой. Суммарное значение проводимости по пропантному и кислотному модулю может быть принято при условии подбора коэффициентов остаточной проводимости по фактическим данным на участке.
Объем растворенной породы определяется только по кислотному модулю и принимается по этому значению.

Таким образом, получены обоснованные источники данных при моделировании кислотно-пропантных ГРП с использованием двух модулей симулятора. На рисунке 2 показан пример расчета, в котором применен представленный принцип комплексирования.

Применение комплексирования базовых единиц модедирования при одновременной инициации трещины ГРП в разделенных интервалах

В ряде случаев проводится ГРП с одновременной закачкой жидкости разрыва в несколько интервалов перфорации. При этом, в зависимости от расстояния между интервалами и механическими напряжениями в области между интервалов может создаваться как две отдельные трещины, так и единая трещина ГРП.

В случае прогнозирования единой трещины ГРП, для корректной оценки создаваемой трещины и наполнения баз данных рекомендуется указать в симуляторе интервал обработки как единый, с целью получения обобщенных результатов расчета.

Если расстояние, механическое напряжение и условия закачки между интервалами инициации способствуют формированию отдельных трещин, в выгрузке симулятора будет содержаться две базовые единицы расчета. Дальнейшая работа с полученными базовыми единицами зависит от структурных особенностей. Если обрабатываемые интервалы рассматриваются как отдельные объекты разработки, то полученные базовые единицы необходимо рассматривать и хранить в базах данных отдельно. В случае, если интер- 


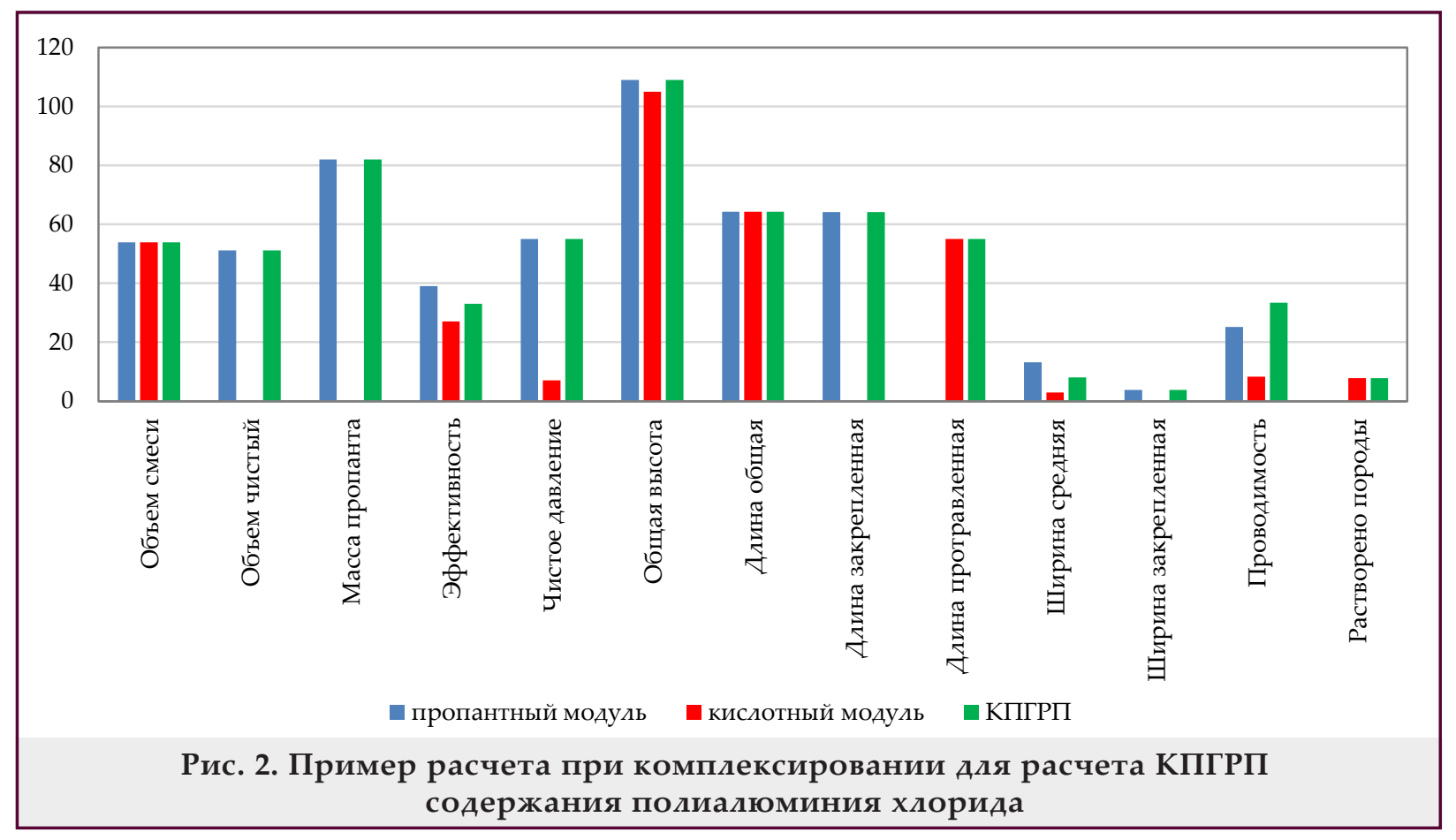

валы разделены, но относятся к одному объекту разработки и процесс ГРП рассматривается как интенсификация данного объекта в целом, полученные значения базовых единиц должны быть объединены для последующего анализа. Не рекомендуется объединять интервады, значительно отличающиеся по колдекторским и механическим свойствам.

Ниже в таблице 2 представлен принцип объединения данных.

Жидкость разрыва распределяется по интервалам в соответствии с формированием и ростом трещин. При этом сохраняется материальный баланс, а показатели общего объема жидкости и пропанта определяются как сумма показателей по зонам обработки.

Эффективность жидкости и чистое давление разрыва для каждого интервала будет отличаться в зависимости от условий. Тем не менее, если для оценки процесса ГРП принято объединенное значение, корректно использовать среднее арифметическое данных показателей.

Общая высота трещины часто используется для оценки эффективности. Для этих целей, чтобы величина характеризовала высоту, охваченную трещиной, необходимо сложить высоты трещин по интервалам.

Гидравлическая, а также закрепленная пропантом или протравленная кислотой длина трещины используется для оценки эффективности,

Принцип объединения данных

Таблица 2

\begin{tabular}{|c|c|}
\hline \multicolumn{2}{|c|}{ Принцип объединения данных } \\
\hline Параметр & Принимаемое значение \\
\hline Общий объем смеси разрыва* & $\mathrm{A}+\mathrm{5}$ \\
\hline Общий объем чистой жидкости & $\mathrm{A}+\mathrm{B}$ \\
\hline Масса пропанта по фракциям* & $\mathrm{A}+\mathrm{B}$ \\
\hline Эффективность жидкости разрыва & $0.5 \cdot(\mathrm{A}+\mathrm{Б})$ \\
\hline Чистое давление разрыва & $0.5 \cdot(\mathrm{A}+\mathrm{Б})$ \\
\hline Общая высота трещины & $\mathrm{A}+\mathrm{B}$ \\
\hline Гидравдическая длина трещины & $\max (\Pi, K)$ \\
\hline Длина трещины, закрепленная пропантом ${ }^{*}$ & $\max (\Pi, \mathrm{K}), 0.5 \cdot(\mathrm{A}+\mathrm{Б})$ \\
\hline Длина трещины, протравленная кислотой ${ }^{* *}$ & $\max (\Pi, \mathrm{K}), 0.5 \cdot(\mathrm{A}+\mathrm{Б})$ \\
\hline Средняя гидравдическая ширина трещины & $0,5 \cdot(\mathrm{A}+\mathrm{Б})$ \\
\hline Ширина трещины, закрепленная пропантом * & $0.5 \cdot(\mathrm{A}+\mathrm{5})$ \\
\hline Проводимость трещины & $\mathrm{A}+\mathrm{B}$ \\
\hline Объем растворенной породы* & $\mathrm{A}+\mathrm{B}$ \\
\hline
\end{tabular}

Примечание: А - расчет для первой зоны, Б - расчет для второй зоны, * - параметры только для пропантных ГРП, ** - параметры только для кислотного ГРП. 
а также для оценки рисков. Максимальное значение позводит провести оценку рисков, а среднее арифметическое - оценку эффективности.

Средняя гидравлическая и закрепленная пропантом ширина трещины - это средние показатели, среднее арифметическое которых позволяет оценить проведенный процесс в целом.

Проводимость трещины и объем растворенной породы используются для оценки эффективности, должны использоваться суммы показателей.

На рисунке 3 представлен пример комплексирования для двух зон пропантного ГРП для случая оценки эффективности проведенного процесса, д,я которого применен представленный принцип.

\section{Применимость, альтернативные решения и выводы}

Предлагаемый способ применим для случаев проведения гибридных кислотно-пропантных ГРП, а также при одновременной обработке нескольких интервалов. При этом подразумевается, что в применяемой стратегии моделирования ГРП на рассматриваемом месторождении принято исподьзование псевдо-трехмерных моделей распространения трещины ГРП.

Альтернативным способом учета данных особенностей технологии является доработка промышленного симулятора ГРП, в результате которой базовая единица расчета будет содержать подный набор требуемых данных. В отличие от предложенного способа, это потребует значительных вложений, а в случае применения симуляторов сторонних разработчиков, не представляется возможным.

Другим альтернативным решением для гибридного кислотно-пропантного ГРП является рассмотрение процесса как кислотного, без модедирования в пропантном модуле. Это привело бы к снижению точности определения геометрических и фильтрационных свойств трещины.

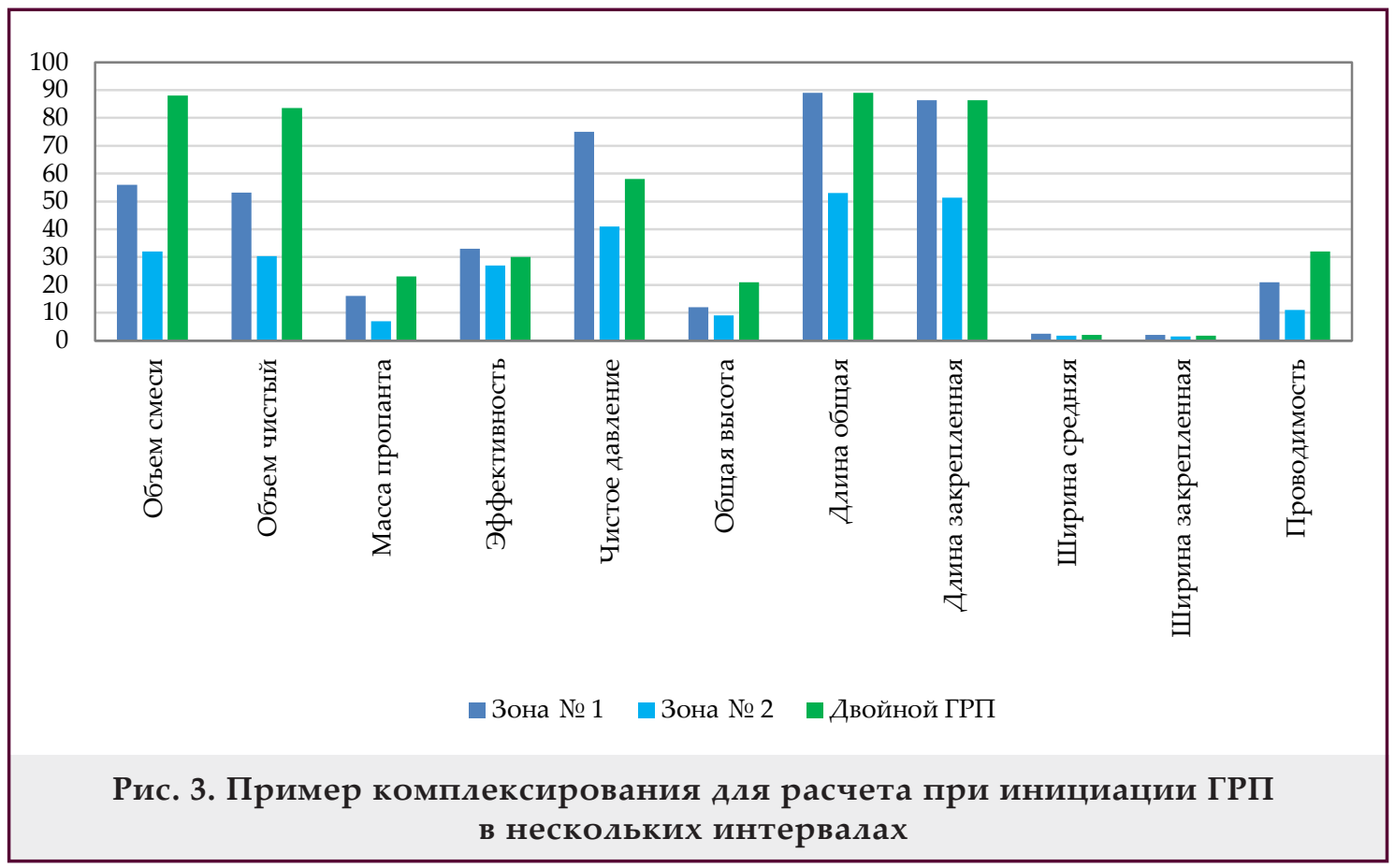

\section{Выводы}

1. Получен способ исподьзования стандартного симулятора ГРП с псевдо-трехмерной моделью распространения трещины для работы по гибридной технологии кислотного-пропантного ГРП.

2. Корректное комплексирование результатов моделирования в пропантном и кислотном модуле позволяет использовать стандартный симулятор для оценки и подготовки массива данных для последующего статистического анализа.

3. Получен способ формирования данных результатов моделирования для случая одновременной обработки нескольких интервалов перфорации с формированием отдельных трещин, относящихся к одному объекту разработки.

4. Применение способа комплексирования для оценки результатов моделирования, в которых содержатся данные для ряда трещин в пределах рассматриваемого пласта позволяет оценивать эффективность и накапливать массив данных для анадиза, в том числе для корректного сравнения со случаями создания единичных трещин в рассматриваемом коляекторе. 


\section{Питература}

1. Минниханов, Р. Н., Маганов, Н. У., Хисамов, Р. С. (2016). О создании научных подигонов по изучению трудноизвлекаемых запасов нефти в Татарстане. Нефтяное хозяйство, 8, 60-63.

2. Мухаметшин, В. В. (2018). Обоснование трендов повышения степени выработки запасов нефти нижнемедовых отложений Западной Сибири на основе идентификации объектов. Известия Томского политехнического университета. Инжиниринг георесурсов, 329(5), 117-124.

3. Велиев, Э. Ф. (2021). Полимерно-дисперсная система для изменения фильтрационных потоков в пласте. Prospecting and Development of Oil and Gas Fields, 1(78), 61-72.

4. Рогачев, М. К., Мухаметшин, В. В. (2018). Контродь и регулирование процесса солянокислотного воздействия на призабойную зону скважин по геолого-промысловым данным. Записки Горного института, 231, 275-280.

5. Муслимов, Р. Х. (2009). Особенности разведки и разработки нефтяных месторождений в условиях рыночной экономики. Казань: ФЭН.

6. Рабаев, Р. У., Чибисов, А. В., Котенев, А. Ю. и др. (2021). Математическое модедирование растворения карбонатных коллекторов и прогнозирование эффективности регулируемой солянокислотного воздействия. SOCAR Proceedings, 2, 40-46.

7. Мухаметшин, В. В. (2020). Повышение эффективности управления объектами добычи нефти с использованием метода аналогий. SOCAR Proceedings, 4, 42-50.

8. Хузин, Р. Р., Бахтизин, Р. Н., Андреев, В. Е. и др. (2021). Интенсификация добычи нефти методом гидравдического сжатия пласта. SOCAR Proceedings, SI1, 98-108.

9. Новиков, М. Г., Исламов, А. И., Тахаутдинов, Р. Ш. (2021). Эволюция методов интенсификации добычи в процессе разработки залежей турнейского яруса месторождений компании "Шешмаойл" - от кисдотного воздействия до гибридного проппантного гидравдического разрыва пласта. Нефть. Газ. Новации, 3(244), 58-61.

10. Мухаметшин, В. Ш., Зейгман, Ю. В., Андреев, А. В. (2017). Экспресс-оценка потенциала добывных возможностей залежей для определения эффективности применения нанотехнологий и необходимости стимулирования ввода их в разработку. Нанотехнологии в строительстве, 9(3), $20-34$.

11. Economides, J. M., Nolte, K. I. Reservoir stimulation. (2000). West Sussex, England: John Wiley and Sons.

12. Якупов, Р. Ф., Хакимзянов, И. Н., Мухаметшин, В. В., Кулешова, А. С. (2021). Использование гидродинамической модели при создании обратного конуса нефти в условиях водонефтяных зон. SOCAR Proceedings, 2, 54-61.

13. Гасумов, Э. Р., Гасумов, Р. А. (2020). Управление инновационными рисками при выполнении геолого-технических (технологических) мероприятий на нефтегазовых месторождениях. SOCAR Proceedings, 2, 8-16.

14. Хакимзянов, И. Н., Мухаметшин, В. Ш., Бахтизин, Р. Н., Шешдиров, Р. И. (2021). Определение объемного коэффициента сетки скважин для оценки конечного коэффициента нефтеизвлечения при разработке залежей нефти горизонтальными скважинами. SOCAR Proceedings, 2, 47-53.

15. Сулейманов, Б. А., Исмайлов, Ф. С., Велиев, Э. Ф., Дышин, О. А. (2013). О вдиянии наночастиц на прочность полимерных гелей, применяемых в нефтедобыче. SOCAR Proceedings, 2, 24-28.

16. Мухаметшин, В. В., Кулешова, А. С. (2019). Обоснование систем заводнения низкопродуктивных залежей нефти в условиях ограниченного объема информации. SOCAR Proceedings, 2, 16-22.

17. Велиев, Э. Ф. (2020). Обзор современных методов увеличения нефтеотдачи пласта с применением потокоотклоняющих технологий. SOCAR Proceedings, 2, 50-66.

18. Мухаметшин, В. Ш., Хакимзянов, И. Н., Бахтизин, Р. Н., Кулешова, А. С. (2021). Дифференциация и группирование сложнопостроенных залежей нефти в карбонатных коллекторах в решении задач управления разработкой, SOCAR Proceedings, SI1, 88-97.

19. Велиев, Э. Ф. (2020). О механизмах удерживания полимера пористой средой. SOCAR Proceedings, 3, 126-134.

20. Ахметов, Р. Т., Маляренко, А. М., Кулешова, А. С. и др. (2021). Количественная оценка гидравлической извилистости коллекторов нефти и газа Западной Сибири на основе капилляриметрических исследований. SOCAR Proceedings, 2, 77-84.

21. Wang, M., Chen, S., Lin, M. (2018). Enhancing recovery and sensitivity studies in an unconventional tight gas condensate reservoir. Petroleum Science, 15, 305-318.

22. Андреев, А. В., Мухаметшин, В. Ш., Котенёв, Ю. А. (2016). Прогнозирование продуктивности залежей в карбонатных коллекторах с трудноизвлекаемыми запасами. SOCAR Proceedings, 3, 40-45.

23. López-Comino, J. A., Cesca, S., Jarosławski, J., et al. (2018). Induced seismicity response of hydraulic fracturing: results of a multidisciplinary monitoring at the Wysin site, Poland. Scientific Reports, 8.

24. Кулешова, А. С., Фаттахов, И. Г., Султанов, Ш. Х. др. (2021). Опыт проведения многозонного кислотного ГРП на месторождении ПАО «Татнефть». SOCAR Proceedings, SI11, 68-76.

25. Нургалиев, О. Т., Водченко, Ю. А. (2016). Радиоизотопный метод и измерительный ком- 
плекс РИКП-01 для экспрессного определения концентрации проппанта в рабочих смесях, применяемых при гидравдическом разрыве нефтегазосодержащих пластов. Автоматизациия, телемеханизация и связь в нефтяной промышленности, 8, 24-28.

26. Хакимзянов, И. Н., Мухаметшин, В. Ш., Бахтизин, Р. Н. и др. (2021). Обоснование необходимости учета интерференции между скважинами при разряжении сетки скважин на пашийском горизонте Бавдинского месторождения. SOCAR Proceedings, SI1, 77-87.

27. Юсифов, Т. Ю., Попов, В. Г., Фаттахов, И. Г. и др. (2015). Гидроразрыв пласта и его эффективное применение. Научное обозрение, 8, 23-28.

28. Wang, L., Dong, Z., Li, X., Xia, Z. (2018). A multi-scale flow model for production performance analysis in shale gas reservoirs with fractal geometry. Scientific Reports, 8.

29. Сулейманов, Б. А., Велиев, Э. Ф. (2016). О влиянии гранулометрического состава и наноразмерных добавок на качество изоляции затрубного пространства в процессе цементирования скважин. SOCAR Proceedings, 4, 4-10.

30. Yakupov, R. F., Mukhametshin, V. Sh., Tyncherov, K. T. (2018). Filtration model of oil coning in a bottom water-drive reservoir. Periodico Tche Quimica, 15(30), 725-733.

31. Ahmed Quosay, A., Knez, D., Ziaja, J. (2020). Hydraulic fracturing: new uncertainty based modeling approach for process design using Monte Carlo simulation technique. PLoS ONE, 15(7).

32. Мухаметшин, В. В., Андреев, В. Е., Дубинский, Г. С. и др. (2016). Исподьзование принципов системного геолого-технологического прогнозирования при обосновании методов воздействия на пласт. SOCAR Proceedings, 3, 46-51.

33. Alvarado, V., Reich, E.-M., Yunfeng, Yi, Potsch, K. (2006, June). Integration of a risk management tool and an analytical simulator for assisted decision-making in IOR. SPE-100217-MS. In: SPE Europec/ EAGE Annual Conference and Exhibition. Society of Petroleum Engineers.

34. Сергеев, В. В., Беленкова, Н. Г., Зейгман, Ю. В., Мухаметшин, В. Ш. (2017). Физические свойства эмульсионных систем с содержанием наночастиц $\mathrm{SiO}_{2}$. Нанотехнологии в строительстве, 9(6), 37-64.

35. Zhang, F., Ma, G., Liu, X., et al. (2018). Experimental analysis of multiple factors on hydraulic fracturing in coalbed methane reservoirs. PLoS ONE, 13(4).

36. Mardashov, D. V., Rogachev, M. K., Zeigman, Yu. V., Mukhametshin, V.V. (2021). Well killing technology before workover operation in complicated conditions. Energies, 14(3), 654, 1-15.

37. He, L., Chen, Y., Zhao, H., et al. (2018). Game-based analysis of energy-water nexus for identifying environmental impacts during Shale gas operations under stochastic input. The Science of the Total Environment, 627, 1585-1601.

38. Мухаметшин, В. В., Андреев, В. Е. (2018). Повышение эффективности оценки результативности технологий, направленных на расширение использования ресурсной базы месторождений с трудноизвлекаемыми запасами. Известия Томского политехнического университета. Инжиниринг георесурсов, 329(8), 30-36.

\section{References}

1. Minnikhanov, R. N., Maganov, N. U., Khisamov, R. S. (2016). On creation of research and testing facilities to promote study of nonconventional oil reserves in Tatarstan. Oil Industry, 8, 60-63.

2. Mukhametshin, V. V. (2018). Rationale for trends in increasing oil reserves depletion in Western Siberia cretaceous deposits based on targets identification. Bulletin of the Tomsk Polytechnic University. Geo Assets Engineering, 329(5), 117-124.

3. Veliyev, E. F. (2021). Polymer dispersed system for in-situ fluid diversion. Prospecting and Development of Oil and Gas Fields, 1(78), 61-72.

4. Rogachev, M. K., Mukhametshin, V. V. (2018). Control and regulation of the hydrochloric acid treatment of the bottomhole zone based on field-geological data. Journal of Mining Institute, 231, 275-280.

5. Muslimov, R. Kh. (2009). Features of exploration and development of oil fields in a market economy. Kazan: FEN.

6. Rabaev, R. U., Chibisov, A. V., Kotenev, A. Yu., et al. (2021). Mathematical modelling of carbonate reservoir dissolution and prediction of the controlled hydrochloric acid treatment efficiency. SOCAR Proceedings, 2, 40-46.

7. Mukhametshin, V. V. (2020). Oil Production Facilities Management Improving Using the Analogy Method. SOCAR Proceedings, 4, 42-50.

8. Khuzin, R. R., Bakhtizin, R. N., Andreev, V. E., et al. (2021). Oil Recovery Enhancement by Reservoir Hydraulic Compression Technique Employment. SOCAR Proceedings, SI1, 98-108.

9. Novikov, M. G., Islamov, A. I., Takhautdinov, R. Sh. (2021). Evolution of production intensification methods in the course of development of deposits in the tournaisian stage of Sheshmaoil company's oilfields: from acid stimulation to hybrid fracturing. Oil. Gas. Innovations, 3(244), 58-61.

10. Mukhametshin, V. Sh., Zeigman, Yu. V., Andreev, A. V. (2017). Rapid assessment of deposit production capacity for determination of nanotechnologies application efficiency and necessity to stimulate their development. Nanotechnologies in Construction, 9(3), 20-34. 
11. Economides, J. M., Nolte, K. I. Reservoir stimulation. (2000). West Sussex, England: John Wiley and Sons.

12. Yakupov, R. F., Khakimzyanov, I. N., Mukhametshin, V. V., Kuleshova, L. S. (2021). Hydrodynamic model application to create a reverse oil cone in water-oil Zones. SOCAR Proceedings, 2, 54-61.

13. Gasumov, E. R., Gasumov, R. A. (2020). Innovative risk management for geological and technical (technological) measures at oil and gas fields. SOCAR Proceedings, 2, 8-16.

14. Khakimzyanov, I. N., Mukhametshin, V. Sh., Bakhtizin, R. N., Sheshdirov, R. I. (2021). Determination of well spacing volumetric factor for assessment of final oil recovery in reservoirs developed by horizontal wells. SOCAR Proceedings, 2, 47-53.

15. Suleimanov, B. A., Ismailov, F. S., Veliyev, E. F., Dyshin, O. A. (2013). The influence of light metal nanoparticles on the strength of polymer gels used in oil industry. SOCAR Proceedings, 2, 24-28.

16. Mukhametshin, V. V., Kuleshova, L. S. (2019). Justification of low-productive oil deposits flooding systems in the conditions of limited information amount. SOCAR Proceedings, 2, 16-22.

17. Veliyev, E. F. (2020). Review of modern in-situ fluid diversion technologies. SOCAR Proceedings, 2, 50-66.

18. Mukhametshin, V. Sh., Khakimzyanov, I. N., Bakhtizin, R. N., Kuleshova, L. S. (2021). Differentiation and grouping of complex-structured oil reservoirs in carbonate reservoirs in development management problems solving. SOCAR Proceedings, SI1, 88-97.

19. Veliyev, E. F. (2020). Mechanisms of polymer retention in porous media. SOCAR Proceedings, 3, 126-134.

20. Akhmetov, R. T., Malyarenko, A. M., Kuleshova, L. S., et al. (2021). Quantitative assessment of hydraulic tortuosity of oil and gas reservoirs in western siberia based on capillarimetric studies. SOCAR Proceedings, 2, 77-84.

21. Wang, M., Chen, S., Lin, M. (2018). Enhancing recovery and sensitivity studies in an unconventional tight gas condensate reservoir. Petroleum Science, 15, 305-318.

22. Andreev, A. V., Mukhametshin, V. Sh., Kotenev, Yu. A. (2016). Deposit Productivity Forecast in Carbonate Reservoirs with Hard to Recover Reserves. SOCAR Proceedings, 3, 40-45.

23. López-Comino, J. A., Cesca, S., Jarosławski, J., et al. (2018). Induced seismicity response of hydraulic fracturing: results of a multidisciplinary monitoring at the Wysin site, Poland. Scientific Reports, 8.

24. Kuleshova, L. S., Fattakhov, I. G., Sultanov, Sh. Kh., et al. (2021). Experience in Conducting Multi-Zone Hydraulic Fracturing on the Oilfield of PJSC «Tatneft». SOCAR Proceedings, SI1, 68-76.

25. Nurgaliev, O. T., Volchenko, Y. A. (2016). Radioisotope technique and RIKP-01 measuring facility for express estimation of proppant concentration in mixtures used in hydraulic fracturing of oil and gasbearing formations. Automation, Telemechanization and Communication in Oil Industry, 8, 24-28.

26. Khakimzyanov I. N., Mukhametshin V. Sh., Bakhtizin R. N., et al. (2021). Justification of necessity to consider well interference in the process of well pattern widening in the Bavlinskoye oil field pashiyan formation. SOCAR Proceedings, SI1, 77-87.

27. Yusifov, T. Yu., Popov, V. G., Fattakhov, I. G., et al. (2015). Hydraulic fracturing and its effective application. Scientific Review, 8, 23-28.

28. Wang, L., Dong, Z., Li, X., Xia, Z. (2018). A multi-scale flow model for production performance analysis in shale gas reservoirs with fractal geometry. Scientific Reports, 8.

29. Suleimanov, B. A., Veliyev, E. F. (2016). The effect of particle size distribution and the nanosized additives on the quality of annulus isolation in well cementing. SOCAR Proceedings, 4, 4-10.

30. Yakupov, R. F., Mukhametshin, V. Sh., Tyncherov, K. T. (2018). Filtration model of oil coning in a bottom water-drive reservoir. Periodico Tche Quimica, 15(30), 725-733.

31. Ahmed Quosay, A., Knez, D., Ziaja, J. (2020). Hydraulic fracturing: new uncertainty based modeling approach for process design using Monte Carlo simulation technique. PLoS ONE, 15(7).

32. Mukhametshin, V. V., Andreev, V. E., Dubinsky, G. S., et al. (2016). The usage of principles of system geological-technological forecasting in the justification of the recovery methods. SOCAR Proceedings, 3, 46-51.

33. Alvarado, V., Reich, E.-M., Yunfeng, Yi, Potsch, K. (2006, June). Integration of a risk management tool and an analytical simulator for assisted decision-making in IOR. SPE-100217-MS. In: SPE Europed EAGE Annual Conference and Exhibition. Society of Petroleum Engineers.

34. Sergeev, V. V., Belenkova, N. G., Zeigman, Yu. V., Mukhametshin, V. Sh. (2017). Physical properties of emulsion systems with $\mathrm{SiO}_{2}$ nanoparticles. Nanotechnologies in Construction, 9(6), 37-64.

35. Zhang, F., Ma, G., Liu, X., et al. (2018). Experimental analysis of multiple factors on hydraulic fracturing in coalbed methane reservoirs. PLOS ONE, 13(4).

36. Mardashov, D. V., Rogachev, M. K., Zeigman, Yu. V., Mukhametshin, V.V. (2021). Well killing technology before workover operation in complicated conditions. Energies, 14(3), 654, 1-15.

37. He, L., Chen, Y., Zhao, H., et al. (2018). Game-based analysis of energy-water nexus for identifying environmental impacts during Shale gas operations under stochastic input. The Science of the Total Environment, 627, 1585-1601.

38. Mukhametshin, V. V., Andreev, V.E. (2018). Increasing the efficiency of assessing the performance of techniques aimed at expanding the use of resource potential of oilfields with hardto-recover reserves. Bulletin of the Tomsk Polytechnic University. Geo Assets Engineering, 329(8), 30-36. 


\title{
Компдексирование результатов модедирования ГРП при проведении гибридных кислотно-пропантных обработок и при одновременной инициации трещины ГРП в разделенных интервалах
}

\author{
И.Г. Фаттахов ${ }^{1,2}$, А.С. Кулешова ${ }^{1}$, Р.Н. Бахтизин ${ }^{1}$, \\ В.В. Мухаметиин ${ }^{1}$ А.В. Кочетков ${ }^{2}$ \\ ${ }^{1}$ Уфимский государственный нефтяной \\ технический университет, Уфа, Россия \\ ${ }^{2}$ ПАО «Татнефть» имени В.Д. Шашина, \\ Альметьевск, Россия

\section{Реферат}

Цель работы - обосновать и сформулировать принципы формирования данных при множественном резудьтате модедирования гидравдического разрыва пласта (ГРП). Качественные данные для оценки, взаимного сравнения и последующего статистического анализа характеризуются единственным численным значением для каждого рассматриваемого параметра ГРП. Для ряда технодогий ГРП может возникнуть неопределенность в связи с получением нескольких значений для рассматриваемого параметра. Научная новизна работы закдючается в обосновании нового подхода для оценки получаемого ряда данных при моделировании ГРП. Ряд данных может быть получен как при образовании и модедировании нескольких трещин ГРП, так и для одной трещины при расчете в разных модулях симулятора. В результате была разработана методика комплексирования, позволяющая сформировать единообразный массив данных независимо от количества элементов в результатах моделирования ГРП.

Ключевые слова: гидравдический разрыв пласта; кислотно-пропантный гидравлический разрыв пласта; гидравдический разрыв слоистых пород; моделирование гидравдического разрыва пласта; псевдо-трехмерная модедь трещины; подготовка данных, статистический анализ.

\section{Ayrı-ayrı intervallarda hibrid propan turşusi ilə işlənmənin aparılması və eyni vaxtda LHY çatlarının başlanğıcı zamanı LHY-nın modelləşdirməsi nəticələrinin komplekslənməsi}

\author{
I.Q. Fattaxov 1,2, L.S. Kuleşova, ${ }^{1}$, R.N.Bahtizin ${ }^{1}$, \\ V.V. Muxametşin ${ }^{1}$, A.V. Koçetkov ${ }^{2}$ \\ ${ }^{1}$ Ufa Dövlət Neft Texniki Universiteti, Ufa, Rusiya; \\ ${ }^{2}$ V.D. Şaşın adına "TATNEFT" ASC, Almetyevsk, Rusiya
}

\begin{abstract}
Xülasə
Məqalənin məqsədi layın hidravlik yarılmasının (LHY) modelləşdirilməsinin çoxsaylı nəticəcələri ilə məlumatların formalaşdırılması prinsiplərini əsaslandırmaq və formalaşdırmaqdan ibarətdir. Qiymətləndirmə, qarşılıqlı müqayisə və statik analiz üçün keyfiyyətli məlumatlar baxılan hər bir LHY parametri üçün vahid ədədi qiymətlə xarakterizə olunur. Bir sıra LHY texnologiyaları üçün baxılan parametrə görə müxtəlif qiymətlərin alınması səbəbindən qeyri-müəyyənlik yarana bilər. İşin elmi yeniliyi LHYnin modelləşdirilməsi zamanı alınan verilənlər sırasının qiymətləndirilməsi üçün yeni yanaşmanın əsaslandırılmasından ibarətdir. Verilənlər sırası simulyatorun müxtəlif modullarında hesablanma zamanı həm LHY-nın bir neçə çatının, həm də bir çatın modelləşdirilməsi zamanı əldə edilə bilər. Nəticədə LHY-nın modelləşdirilməsi nəticələrində elementlərin sayından asılı olmayaraq vahid verilənlər massivini formalaşdırmağa imkan verən kompleksləmə metodikası işlənib hazırlanmışdır.
\end{abstract}

Açar sözlar: layın hidravlik yarılması; turşu-propan ilə layın hidravlik yarılması; laylı süxurların hidravlik yarılması; layın hidravlik yarılmasının modelləşdirilməsi; psevdoüçölçülü çat modeli; verilənlərin hazırlanması; statistik analiz. 